\title{
Yoga to Reduce Leisure Constraints for Residents of Assisted Living Facilities
}

Em V. Adams ${ }^{1,}{ }^{*}$, Marieke Van Puymbroeck ${ }^{2}$, Brandi M. Crowe ${ }^{2}$, Cynthia L. S. Pury ${ }^{2}$, Arlene A. Schmid $^{3}$

1. Herbert H. Lehman College, Bronx, NY, USA; E-Mail: emilie.adams@lehman.cuny.edu

2. Clemson University, Clemson, SC, USA; E-Mails: mvp@clemson.edu; bmcrowe@clemson.edu; cpury@clemson.edu

3. Colorado State University, Fort Collins, CO, USA; E-Mail: arlene.schmid@colostate.edu

* Correspondence: Em V Adams; E-Mail: emilie.adams@lehman.cuny.edu

Academic Editor: James S. Powers

Special Issue: Yoga in Older Adults

OBM Geriatrics

2020 , volume 4 , issue 4

doi:10.21926/obm.geriatr.2004135
Received: August 19, 2020

Accepted: October 12, 2020

Published: October 20, 2020

\begin{abstract}
Residents of assisted living facilities face leisure constraints (barriers to leisure activities) at higher rates than their community-dwelling peers. Past research suggests yoga may be an effective intervention to decrease leisure constraints to physical activity. Therefore, the purpose of this study was to evaluate the impact of an eight-week yoga intervention on the leisure constraints of residents of assisted living facilities. The study employed a convergent mixed methods design to assess the impact of a 50-minute group yoga intervention, offered twice a week for eight weeks by a Certified Yoga Therapist. The intervention was implemented at four different assisted living facilities in the Southeastern United States. Pre- and post-quantitative measures were collected to assess overall leisure constraints, limitations in functional fitness, and pain interference. Qualitative data were collected via focus groups post-yoga intervention to determine participants' perspectives on changes in leisure constraints. A total of 15 participants completed the study. Data analysis revealed significant improvements in two of the four functional fitness measures: upper body
\end{abstract}

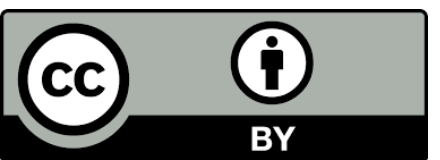

(C) 2020 by the author. This is an open access article distributed under the conditions of the Creative Commons by Attribution License, which permits unrestricted use, distribution, and reproduction in any medium or format, provided the original work is correctly cited. 
endurance (measured by the Arm Curl Test), and trunk stability (measured by the Function in Sitting Test). No significant improvements were observed in pain interference, or overall leisure constraints. Qualitative results indicated participants used yoga to help engage in daily activities such as housework, sleeping, and walking. Additionally, participants reported using yoga to help manage pain. In this sample, yoga appears to be a promising intervention to help reduce specific leisure constraints such as a reduction in functional fitness. Additionally, yoga shows some promise as a pain management strategy, warranting further research.

\section{Keywords}

Yoga; leisure constraints; functional fitness; pain; long-term care

\section{Introduction}

Long-term care is an umbrella term encompassing a range of services designed to meet the needs of older adults who need support for health care or activities of daily living [1, 2]. An estimated $60 \%$ of older adults will need long-term care services at some point in their life [1]. Assisted living facilities (ALFs) are a type of long-term care service designed to promote maximum autonomy, while offering 24-hour assistance with personal care, limited health care services, and social and recreational programming [3]. Active engagement in social and recreational activities is associated with many benefits for older adults, including improved cognition, functional fitness, mental health, and reduced frailty [4-8]. However, many residents of ALFs do not engage in recreational programming, especially in physical activity programs [9]. Reasons for low participation vary [10], and can be viewed through the lens of leisure constraints.

The hierarchical theory of leisure constraints describes three types of sequential factors that influence a person's preference and participation in leisure activities [11]. Structural constraints are environmental factors that impact a person's ability to participate. Examples of structural constraints in ALFs include a lack of supplies, inadequate space, inaccessible activities, poor communication from staff, and low staff support [12]. Interpersonal constraints occur at the level of interaction between people. Examples of interpersonal constraints in ALFs include perceived disapproval of family members or other residents [13]. Intrapersonal constraints are the beliefs and abilities within a person that influence their leisure preferences and participation. Examples of intrapersonal constraints in ALFs include pain and pain interference (the extent to which pain inhibits activities), beliefs that activities can be dangerous, and low functional fitness [14-16]. Leisure constraints are encountered hierarchically; intrapersonal constraints are experienced first, followed by interpersonal constraints. Structural constraints are observed only after intrapersonal and interpersonal constraints are negotiated [13].

Excessive leisure constraints can limit participation or reduce the benefits of leisure activities [13]. While leisure constraints are high in long-term care, they may not be inherently negative. When leisure constraint negotiation strategies are intentional and autonomous, leisure constraints can promote individuals prioritizing meaningful activities and reducing participation in less meaningful activities [17-19]. For example, older adults may compensate for declining 
functional ability by adapting activities so they can continue participating in them [20]. Alternatively, they may compensate by discontinuing participation in activities that are less meaningful to conserve energy and prioritize participation in the most meaningful activities [20]. To this extent, leisure constraints can enhance life if the person has the autonomy to engage in intentional leisure constraint negotiation strategies [21].

Researchers found a connection between engagement in a yoga intervention and increased ability to negotiate leisure constraints $[22,23]$. Yoga is a gentle practice that includes physical movement and postures (asana), voluntary controlled breathing (pranayama), and mindful awareness/meditation (dhyana) [24, 25]. Because yoga can be adapted without changing the core principles of the activity, it has the potential of being adapted to be accessible for people with various levels of cognitive and physical functioning [26]. While yoga may improve leisure constraint negotiation strategies $[27,28]$, it also benefits specific intrapersonal constraints including pain intensity and interference [28-30], beliefs regarding physical activity [31], and functional fitness [32, 33].

Because residents of long-term care facilities have significantly higher pain levels [14], negative beliefs toward physical activity [34], and lower functional fitness than their community-dwelling peers [35], they are at risk for continued reductions in activity and functional ability [36]. While researchers have shown that yoga can improve leisure constraint negotiation strategies and increase physical functioning for various populations [37-39], these outcomes have not been tested among individuals participating in yoga in ALFs. Therefore, the purpose of this study was to evaluate the impact of an eight-week yoga intervention on leisure constraints of residents in ALFs. The hypotheses are that after the intervention, participants will experience: 1 ) a reduced impact of overall leisure constraints; 2) a reduction in pain interference; and 3) an improvement in functional fitness.

\section{Materials and Methods}

\subsection{Design of the Study}

A mixed methods convergent design was used to explore the impact of a yoga intervention on the leisure constraints of residents of ALFs. In a convergent mixed methods approach, quantitative and qualitative data strands regarding the same construct are collected concurrently and independently; data strands are initially analyzed separately and then compared to triangulate findings. The present study was part of a larger study that explored the outcomes and feasibility of implementing therapeutic yoga in ALFs [40]. Quantitative data were collected through psychosocial questionnaires and physical performance measures at baseline (T1) and postintervention (T2). Qualitative data were collected through weekly open-ended questions, and post-intervention focus groups and semi-structured interviews. This study was approved by a university institutional review board, and all participants provided informed consent prior to participation.

\subsection{Recruitment}

Participants were recruited from four separate ALFs in South Carolina, United States, that had not offered yoga or other mindfulness-based physical activity in the past five years. The activity 
directors for the respective facilities assisted the principal investigator (PI) in recruiting participants. The PI explained the intervention and the purpose of the study to potential participants, obtained informed consent, and conducted a formal eligibility screening.

To be included in the study, residents must have: been a current resident at the ALF, been willing to provide informed consent, committed to attend the yoga intervention twice a week for eight weeks, demonstrated no contraindications for physical activity (demonstrated by answering no to all questions on the Physical Activity Readiness Questionnaire (PAR-Q) [41] or providing physician approval), and passed a cognitive screener (demonstrated by scoring a three or higher on the MiniCOG[42]). Residents were excluded if they were: currently enrolled in another study, were planning to leave the facility in the next 10 weeks, had a diagnosis of dementia, had scheduled surgeries or other invasive medical treatments in the next 10 weeks, or required ventilator assistance to breathe. Although study participants had to meet specific criteria, residents of the ALF who did not qualify for the study were still able to participate in intervention sessions. A total of 17 participants were recruited from four different ALFs ( $n=4, n=4, n=5, n=4)$.

\subsection{Intervention}

The intervention was an eight-week chair yoga program, delivered in a group format at each ALF twice a week by a Certified Yoga Therapist (C-IAYT). Session length averaged $48 \pm 6$ minutes. The yoga intervention was adapted by the PI (a C-IAYT) from evidence-based sequences that had previously been used with older adults (see Table 1 for list of postures) [32, 43, 44]. Each intervention session included postures (asanas), mindfulness practice (dhyana), breath practice (pranayama), intention (mantra), and a final resting pose (savasana). As the yoga practice progressed, the physical postures and general sequence remained consistent, while the intention, mantra, breath practice, and focus of the practice advanced (see Table 2 for weekly progression). A member of the research team documented any deviations from the planned sequence or modifications and the justification for the change in field notes. Treatment fidelity was observed either in person or through video observation and recorded on a fidelity checklist.

Table 1 Sequence of postures in the yoga practice.

\begin{tabular}{lll}
\hline Yoga component & Physical benefit & Duration \\
\hline Grounding & $\begin{array}{l}\text { Stimulates parasympathetic nervous system } \\
\text { Improves body awareness }\end{array}$ & 2 minutes \\
& Regulate heart rate \\
& Releases endorphins \\
& Provide a focal point for meditation \\
Improved concentration & 1 Minute \\
& Regulate blood pressure, activate para- \\
& $\begin{array}{l}\text { sympathetic nervous system. Reduce 1 Minute } \\
\text { anxiety. }\end{array}$ \\
& Increasing blood flow to muscles and joints, \\
& boosts production of synovial fluid. fascial 16 Min \\
& release
\end{tabular}




\begin{tabular}{|c|c|c|}
\hline $\begin{array}{l}\text { Moving across the } \\
\text { midline }\end{array}$ & $\begin{array}{l}\text { Improves interoception perception of the } \\
\text { body in space }\end{array}$ & $6 \mathrm{~min}$ \\
\hline $\begin{array}{l}\text { Asanas for strength and } \\
\text { flexibility and balance }\end{array}$ & $\begin{array}{l}\text { Increase muscle strength } \\
\text { Increase flexibility of muscles, ligaments and } \\
\text { tendons }\end{array}$ & $31 \mathrm{~min}$ \\
\hline Meditation & $\begin{array}{l}\text { Improve focus } \\
\text { Reducing stress/anxiety } \\
\text { Increase pain tolerance }\end{array}$ & $6 \mathrm{~min}$ \\
\hline Resting pose & Improve interoceptive awareness & $1 \mathrm{~min}$ \\
\hline Moment of connection & Improve social connection & $1 \mathrm{~min}$ \\
\hline
\end{tabular}

Table 2 Weekly progression of yoga practice.

\begin{tabular}{|c|c|c|c|c|}
\hline Week & Mantra & $\begin{array}{l}\text { Pranayama } \\
\text { Practice }\end{array}$ & Asana & Chakra \\
\hline 1 & I feel safe moving my body & Ujjayi & Baddah konasana & Root \\
\hline 2 & $\begin{array}{l}\text { I find joy in moving my body. } \\
\text { I feel powerful moving my }\end{array}$ & Ujjayi & Pelvic tilts & Sacral \\
\hline 3 & $\begin{array}{l}\text { body. I feel joy in my } \\
\text { accomplishments }\end{array}$ & Kapalabhati & Navasana & Solar \\
\hline 4 & I feel worthy of love & Heart charging & $\begin{array}{l}\text { Gomukhasana/ Cactus } \\
\text { arms }\end{array}$ & Heart \\
\hline 5 & I speak from my heart & Sighing & $\begin{array}{l}\text { Bhramari breath with } \\
\text { intuitive movement }\end{array}$ & Throat \\
\hline 6 & I see what matters most & $\begin{array}{l}\text { Alternate nasal } \\
\text { breathing }\end{array}$ & $\begin{array}{l}\text { Moving eyes side to } \\
\text { side, opening one eye at } \\
\text { a time. }\end{array}$ & Third eye \\
\hline 7 & My life has a higher purpose & $\begin{array}{l}\text { Alternate nasal } \\
\text { breathing }\end{array}$ & Tadasana & Crown \\
\hline 8. & $\begin{array}{l}\text { I find peace in movement } \\
\text { and stillness }\end{array}$ & $\begin{array}{l}\text { Breath with } \\
\text { alternating palms } \\
\text { up. }\end{array}$ & $\begin{array}{l}\text { Utthita Tadasana/Sun } \\
\text { salutation }\end{array}$ & $\begin{array}{l}\text { Sushumna } \\
\text { nadi }\end{array}$ \\
\hline
\end{tabular}

\subsection{Data Collection}

Based on the leisure constraints framework [11], the most common leisure constraints that occur within ALFs were measured using both quantitative and qualitative approaches. Participants met with the PI before the first day of the intervention to provide demographic information and complete baseline psychosocial questionnaires and physical performance measures. Following the eight-week intervention, a member of the research team re-administered the psychosocial questionnaires and physical performance measures. Qualitative data (semi-structured interviews and focus groups) were collected after the intervention. 


\subsubsection{Demographics}

Researchers collected demographic information, including age, gender, marital status, race, education level, general health information, previous yoga experience, and length of time living in an ALF at baseline. Additionally, participants' provided information regarding their recreation and leisure engagement, including the frequency and duration of activities at pre- and post-testing.

\subsubsection{Psychosocial Questionnaires}

Participants completed psychosocial questionnaires to assess their perspectives of leisure constraints. The questionnaires included assessment for overall leisure constraints to physical activity, as well as the specific intrapersonal leisure constraint of pain intensity and interference.

\subsubsection{Leisure Constraints Scale}

This 20-item self-report instrument assesses perceived structural, interpersonal, and intrapersonal constraints to physical activity $[22,45]$. Participants were asked to rate the extent to which they agreed with statements regarding leisure constraints using a five-point scale ranging from one (strongly agree) to five (strongly disagree). Sample statements include "I'm too tired," "I'm afraid of getting hurt," and "it's not important for me to be physically active." Potential scores range from 20-100 with a higher score indicating higher levels of leisure constraints.

\subsubsection{Pain, Enjoyment, General Activity Scale (PEG)}

The PEG scale is a brief three-item measure of the impact of pain in daily life [46]. It asks participants to rate their pain intensity and interference on a scale from zero (no pain or no interference) to 10 (pain as bad as I can imagine or complete interference) [46]. Total scores range may from 0-30, and higher scores indicate higher pain intensity and interference.

\subsubsection{Performance Measures}

The present study evaluated functional fitness (fitness needed to engage in daily activities including strength, flexibility, and balance) using all of the seated assessments from the Senior Fitness Test manual [47], as well as a measure of sitting balance and trunk stability [48]. These measures are widely used in long-term care and are considered appropriate in both task and instruction for this population [35].

\subsubsection{The Chair Sit and Reach Test}

The Chair Sit and Reach Test measure assesses lower body flexibility. Participants sit in a chair, extend and straighten one leg, flex the foot, and reach toward their toes with extended fingers [49]. The distance between fingers tips and toes is measured and recorded to the closest half-inch; if participants cannot reach their toes, it is recorded as a negative number, and if the participant reaches past the toes, the distance is recorded as a positive number. A higher score indicates higher lower body flexibility. 


\subsubsection{The Back-Scratch Test.}

The Back-Scratch Test assesses the flexibility of the upper extremities [47]. Participants reach one arm overhead and bend the elbow bringing the fingers down the spine while the other arm wraps around the back, and the fingers of opposite hands reach toward each other. The distance between the fingertips of the two hands is measured and recorded to the closest half-inch; a gap between the fingertips is recorded as a negative number, and overlap is recorded as a positive number. A higher score indicates higher upper body flexibility.

\subsubsection{Arm Curl Test}

The arm curl test assesses upper body strength [47], and upper body endurance [50, 51]. The test is administered by counting the number of bicep curls participants can complete within 30 seconds [47]. Traditionally a five-pound weight (women) or an eight-pound weight (men) is used; however, in this group, all participants felt using the weight was too challenging and chose to complete the measure with no weight. A higher number of completed bicep curls indicates greater upper body strength and endurance. Since no weight was used, only endurance will be attributed in this study.

\subsubsection{Function in Sitting Test}

This 14-item performance measure assesses sitting balance and trunk stability, including sensory, motor, proactive, reactive, and steady-state balance factors [52]. Participants are asked to complete a series of tasks while sitting, such as leaning to one side, reaching out for an item, and scooting back on a chair. Possible scores range from 0-56 with a higher score indicating greater trunk stability. A change in score of 6.5 or more is considered a minimal clinically important difference [48].

\subsubsection{Qualitative Data Collection}

Each week, participants were asked if they had practiced yoga outside of the group intervention. If they answered affirmatively, they were asked to describe their independent yoga practice. After the completion of the eight-week intervention, the PI conducted semi-structured interviews with each participant that began with open-ended questions about how the participant perceived the impact of yoga, followed by probes as needed to address pre-determined constructs (i.e., structural, interpersonal, and intrapersonal leisure constraints, pain, and functional fitness) related to the leisure constraints model [11]. Interviews consisted of nine questions and lasted approximately 20 minutes. Additionally, to minimize social desirability bias, a member of the research team who had not been involved in implementing the intervention conducted a focus group with the participants at each research site. Focus groups lasted approximately 30 minutes and ranged from three to four people in each group. Interview questions were focused more on individual leisure constraints, while focus groups focused on the impact of yoga. 


\subsection{Data Analysis}

\subsubsection{Quantitative Analysis}

IBM SPSS Statistics for Windows, version 24 (IBM Corp., Armonk, N.Y., USA) was used to analyze quantitative data. Descriptive statistics were computed for all demographic variables, psychosocial questionnaires (Leisure Constraints Scale, PEG), and functional fitness measures (Chair Sit and Reach Test, Back-Scratch Test, Arm Curl Test, Function in Sitting Test). A Shapiro-Wilk test was used to assess normality, and a Kolmogorov-Smirnov test was used to determine if the distribution was normal or non-normal. Hypothesis testing was conducted using either the paired t-test or the Wilcoxon signed-rank test based on the distribution. While a Bonferroni correction would typically be applied for the multiple functional fitness measures related to the third hypothesis, because of the small sample size and exploratory nature of the research, no corrections were made, and the significance value remained at the $p=.05$ level for all measures. Percent change was calculated for each measure between T1 and T2 (percent change $=(\mathrm{T} 2-\mathrm{T} 1 / \mathrm{T} 1) \mathrm{x}$ 100)).

\subsubsection{Qualitative Content Analysis}

Data from semi-structured interviews and focus groups were transcribed verbatim, and each participant was assigned a pseudonym of their choosing. Directed content analysis [53] based on the leisure constraints framework [11] was conducted using NVivo 12 software. First, the text that fit with pre-determined codes of leisure constraints was coded as leisure participation, pain or pain management, and functional fitness (strength, endurance, flexibility). Text that did not fit in one of the pre-determined codes was set aside and analyzed later to determine if it represented a new category or if it fit as a sub-category for a pre-determined code. Coded text was analyzed to ensure it accurately fit the pre-determined themes, and themes were adjusted as needed. Throughout the research process, the PI engaged in bracketing to identify preconceptions about yoga and older adults and ensure trustworthiness by bracketing bias and focusing the research on participant perceptions. Additionally, an external auditor independently reviewed the qualitative data to ensure the accuracy of the analysis. There was a $95 \%$ concurrence between coded themes. Themes that were different were discussed until a consensus was reached.

\subsubsection{Integrating Data Strands}

Quantitative and qualitative results were compared to determine if quantitative and qualitative and results indicated the same results (convergent results) or if results were contradictory (divergent). Member checking occurred after the initial data analysis. Participants were given a written summary, and a brief in-person presentation of the integrated findings. Seventy-three percent of the participants attended the in-person presentation and gave verbal feedback confirming the findings accurately reflected their perceptions. Additionally, to minimize social desirability bias, participants were provided an anonymous feedback form to indicate if they agreed, partially agreed, partially disagreed, or disagreed with the findings, and they had the opportunity to write feedback. All participants in attendance indicated they agreed, and did not provide additional feedback. 


\section{Results}

Overall, results indicated improvements in overall leisure constraints, pain management, and physical fitness. On average, participants attended $75 \%$ of the intervention, and there was an $11.76 \%$ attrition rate due to death and hospitalization.

\subsection{Demographics}

There were 17 residents initially enrolled in the study, and 15 who completed the full intervention. However, some measures had a smaller sample: four participants were unwilling to complete the Leisure Constraints Scale survey, and three participants were unable to complete the Back-Scratch Test due to self-reported shoulder pain/injury. The 15 participants who completed the full intervention had lived in the ALF for a mean of $1.5 \pm 1.6$ years and had a mean age of 82.94 \pm 9.01 years. There were 13 females and two males, all of whom identified as Caucasian, and none of whom reported previous yoga experience. Results are reported according to the pseudonyms participants chose. There was one adverse event during the intervention: a participant left early complaining of shoulder pain, but insisted it was due to a past injury and not yoga. There were no long-term consequences and the participant returned to the next yoga session.

\subsection{Leisure Constraints}

The first hypothesis was that participants would experience a reduction in constraints to leisure. A paired t-test revealed no significant changes in self-reported leisure constraints (Leisure Constraints Scale $(t(10)=.694, p=.504))$ from T1 to T2. There was over a $5 \%$ improvement, indicating a trend of improvement for constraints to physical activity (see Table 3 for a complete report of the percent changes).

Table 3 Pre and post-test outcome measures compared with qualitative results.

\begin{tabular}{|c|c|c|c|c|c|c|c|c|}
\hline Measure & Construct & $\begin{array}{l}\mathrm{T} 1 \mathrm{M} \\
\pm \mathrm{SD}\end{array}$ & & $\begin{array}{l}\text { T2 Mea } \\
\pm \mathrm{SD}\end{array}$ & & $\mathrm{p}$-value & $\begin{array}{l}\text { Percent } \\
\text { Change }\end{array}$ & $\begin{array}{l}\text { Qualitative } \\
\text { Results }\end{array}$ \\
\hline \multicolumn{9}{|l|}{ Leisure } \\
\hline \multirow{2}{*}{$\begin{array}{l}\text { Constraints } \\
\text { Scale }(n=11)\end{array}$} & \multirow{2}{*}{$\begin{array}{l}\text { Leisure } \\
\text { constraints }\end{array}$} & 44.09 & \multirow[t]{2}{*}{ \pm} & 41.64 & \multirow[t]{2}{*}{ \pm} & \multirow{2}{*}{.504} & \multirow{2}{*}{$\begin{array}{l}-5.56 \\
\text { (improved) }\end{array}$} & \multirow{2}{*}{ Divergent } \\
\hline & & 12.49 & & 16.87 & & & & \\
\hline \multicolumn{9}{|l|}{ Pain, } \\
\hline \multicolumn{9}{|l|}{ Enjoyment, } \\
\hline General & \multirow{2}{*}{ Pain } & 2.80 & \multirow[t]{2}{*}{ \pm} & 2.60 & \multirow[t]{2}{*}{ \pm} & \multirow{2}{*}{.737} & \multirow{2}{*}{$\begin{array}{l}-7.69 \\
\text { (improved) }\end{array}$} & \multirow{2}{*}{ Divergent } \\
\hline $\begin{array}{l}\text { Activity Scale } \\
\text { (PEG) }(n=15)\end{array}$ & & 1.97 & & 2.55 & & & & \\
\hline \multirow{3}{*}{$\begin{array}{l}{ }^{*} \text { Chair Sit and } \\
\text { Reach } \quad \text { Test } \\
(n=15)\end{array}$} & \multicolumn{8}{|l|}{ Functional } \\
\hline & fitness: Lower & -3.35 & \pm & -0.55 & \pm & $* 0$ & +83.5 & $\mathrm{NA}$ \\
\hline & $\begin{array}{l}\text { body } \\
\text { flexibility }\end{array}$ & 4.38 & & 4.13 & & & (improved) & NA \\
\hline
\end{tabular}




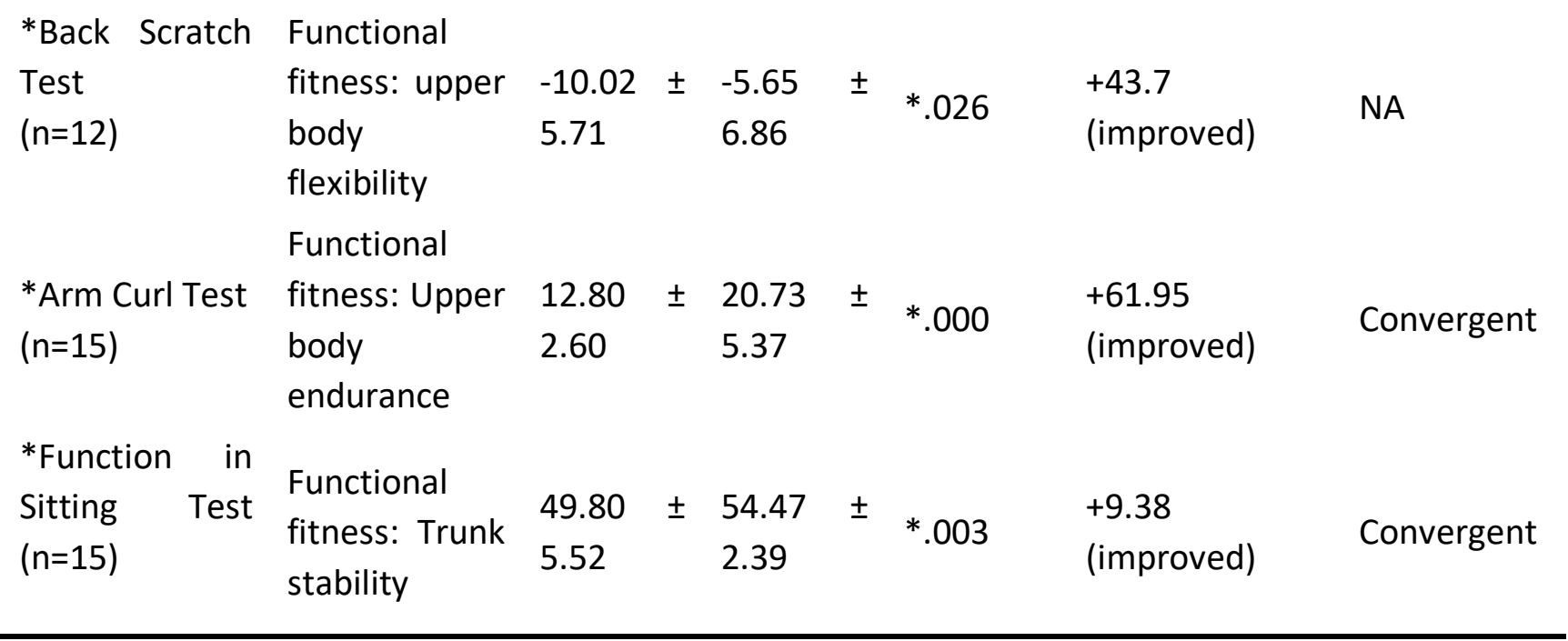

*Indicates a significant change from pre- to post-test.

\subsubsection{Qualitative Results}

Improved engagement in activities was the first category that supported from the qualitative data. During the focus groups, participants identified activities that yoga had positively impacted. Participants identified that they experienced improvements in walking, activities of daily living (ADLs), housework, and sleeping. Anna discussed increased participation in physical activity, saying, "I'm walking more than I used to". Alletta addressed how the intervention impacted her ADLs, saying, "...getting around and doing what l've got to do in my room...taking a bath and stuff like that...l think it helped me do that....". Charles described how he used the meditation and grounding components of the yoga group to help him sleep: "...it helps me to sleep...I start with my head and say you can relax now, then move to my stomach...then my eyes...that's how I put myself to sleep". Participants reported using neck stretches, grounding movements, breathing, and repeating the mantra to assist in completing various activities ranging from putting clothes away, getting ready to stand up out of a chair, or getting ready to sleep. Thus, the quantitative and qualitative results were convergent; we fail to reject the null hypothesis for $\mathrm{H} 1$, and qualitative results did not convey a strong increase in physically active leisure, though participants did report improvements in engagement in other activities.

\subsection{Pain Interference}

The second hypothesis was that participants would experience a reduction in pain interference. A paired t-test revealed no significant changes in self-reported pain interference PEG $(t(14)=.342$, $p=.737$ ) between T1 and T2. Percent change showed a 7.69\% improvement.

\subsubsection{Qualitative Results}

Participant data aligned with the a priori code pain management during directed content analysis. Though not all participants mentioned pain directly, specific conditions such as neuropathy, arthritis, and tight muscles were all coded as pain management. For example, Charles described using yoga to reduce pain, saying, "I have neuropathy. Rocking [my] feet helps relieve it". Diane explained using the mantra to help move throughout the day despite being in pain, saying, 
"...yeah, there's one day I came in, and I was really hurting...but then I said the mantra 'I feel peace moving my body' and when I said the mantra, it helped me get through my pain....". Bobbie discussed the impact of stretching on relieving neck pain, saying, "...l felt tension in my neck...it actually felt better when we were doing it [yoga]" Quantitative and qualitative results were divergent; we fail to reject the null hypothesis, but qualitative findings indicate that yoga was used at times as a pain management strategy that had the potential to reduce pain interference.

\subsection{Functional Fitness}

The third hypothesis was that participants would experience an improvement in functional fitness. A Shapiro-Wilk test revealed a normal distribution for both pre-and post-test Chair Sit and Reach Test measures, a skewed distribution for the pre-test Back-Scratch Test, a normal distribution for both pre- and post-test arm curl test, and a skewed distribution for the post-test Function in Sitting Test. A paired t-test revealed significant improvements in lower body flexibility as measured by the Chair Sit and Reach Test $(t(14)=-2.799, p=.014)$. Wilcoxon's signed-rank test was used to examine upper body flexibility as measured by the Back-Scratch Test between preand post-test, and a significant difference was found $(Z=-2.227, p=.026)$. A paired t-test revealed significant improvements in upper body strength as measured by the arm curl test $(t(14)=-4.811$, $p=.000)$. Finally, a Wilcoxon's signed-rank test revealed a significant improvement in seated balance and trunk stability as measured by the Function in Sitting Test $(Z=-2.945, p=.003)$. Four participants demonstrated a minimal clinically important difference in seated balance and trunk stability. Percent change calculations indicated positive trends for all measures (see Table 3).

\subsubsection{Qualitative Results}

Participant data aligned with the category of physical functioning. The a priori category of functional fitness was supported by the data, but additional codes emerged that included improved physical functioning beyond functional fitness. When asked to identify any changes they noticed during the intervention, many participants discussed items related to enhanced physical functioning that included functional fitness, as well as cognitive functioning and respiratory functioning. For example, Abigail said, "You know it's hard for me to get up and stand on my leg. It seemed like it [yoga] helped me be able to get up better and stand on my leg. It seemed like [my leg] got stronger". Don, discussed perceived improvements in cognitive functioning, saying, "My brain works better". Bobbie indicated an improved ability to breathe, saying, "It's helped my breathing, I noticed that". Qualitative and quantitative results appear to be convergent for physical fitness broadly. Based on the scores on the physical performance measures, we reject the null hypothesis for upper body strength, trunk stability, and lower body and upper body flexibility. However, the qualitative results indicated that participants noticed some general areas of improvement in physical functioning that were measured quantitatively (e.g., respiratory functioning and cognitive functioning). 


\section{Discussion}

The purpose of this mixed-methods study was to evaluate the impact of an eight-week yoga intervention on leisure constraints in ALFs. Results were divergent regarding overall self-reported leisure constraints and pain and were convergent for functional fitness.

Participants did not demonstrate a significant reduction of overall structural, interpersonal, and intrapersonal constraints as measured by the Leisure Constraints Scale post-intervention. One explanation for the lack of change is that those who enrolled in the study already had relatively low levels of leisure constraints so there may not have been room for improvement on the items measured. Alternatively, it may have been that the scale did not adequately capture the leisure constraints of ALF residents. For example, participants reported increased participation in walking and a notable improvement in their ability to engage in and complete housework and ADLs, yet these were not the activities targeted by the questionnaire. While housework and ADLs were not the physical activities specifically targeted by the quantitative measure, past research demonstrates that housework is the primary physical activity through which female older adults reach recommended levels of physical activity [54]. Additionally, while housework is excluded as a leisure activity by some definitions of leisure, there have been reports of individual viewing activities such as housework and ADLs as leisure based on their perceived freedom during the activities [55-57]. Past studies have demonstrated yoga leads to a reduction of leisure constraints or an improvement in leisure constraint negotiation $[23,58]$, and the present study corroborated these findings; participation in walking, housework, ADLs, and sleeping, was improved. Though some of these activities may or may not be considered leisure activities, perhaps a broader measure is needed to assess leisure constraints for older adults who reside in ALFs. Additionally, participants requested written materials be provided so they could practice the sequence on their own. Potentially, providing participants with more resources to practice independently could lead to stronger outcomes.

Quantitative measures did not show significant changes in pain intensity or pain interference, potentially because participants did not endorse high levels of pain at baseline (2.8 on a scale of 0 10). However, qualitative results diverged from quantitative results. Participants reported they used yoga to relieve tension, relax tight muscles, stiffness, and reduce neuropathy that interfered with sleep and other activities. Even though reported pain intensity and interference were not high at T1, qualitative data indicates that yoga was used as a self-management strategy to continue to engage in activities despite the pain that was present. Participants may already reinterpret pain as sensations as part of a pain management strategy, and thus reported low levels of pain when given the scale, but discussed specific sensations in response to open-ended questions. Another explanation could be that participants tried to avoid getting pain medication by reporting low levels of pain. Other researchers have demonstrated that nurse-led strengthening and stretching exercises were effective self-management strategies for individuals experiencing pain in long-term care [59]. The present study indicates that yoga may be used as a self-management strategy or, in other words, as a leisure constraint negotiation strategy in response to pain as a leisure constraint. Some research indicates that increased awareness of body sensations can concurrently lead to an increased awareness of pain [60], but qualitative data did not suggest an increased awareness of pain in the present study. 
The present study reveals a significant improvement in functional fitness between T1 and T2 for lower-body flexibility (as measured by the Chair Sit and Reach Test), upper body flexibility (as measured by the Back-Scratch Test), upper body endurance (as measured by the Arm Curl Test), and trunk stability (as measured by the Function in Sitting Test). Qualitative data indicated that participants perceived an improvement in overall physical functioning, including improved strength, increased flexibility, greater ability to breathe, and better endurance. Many past studies have demonstrated the impact of yoga on improving the functional fitness of older adults and people with chronic illness [32, 44,61], and this study demonstrates functional fitness outcomes are salient in the ALF context. Past research indicates functional fitness is correlated with autonomy in completing ADLs [62]; thus, changes in functional fitness may have influenced the changes in housework and ADLs discussed above.

\section{Limitations}

As with all research, this study had several limitations. First, the sample was a small selfselected sample, who may have had qualitatively different attitudes towards exercise or yoga than those who declined participation; as such, the results cannot be generalized, and the outcomes cannot be attributed solely to yoga. Second, there were limitations with the measures for both overall leisure constraints (Leisure Constraints Scale), upper body flexibility (Back-Scratch Test), and upper body endurance (Arm Curl Test). The items on the Leisure Constraints Scale are written for people living in the community, and the four participants in this study who did not complete the Leisure Constraints Scale stated they did not think the items applied to them. It is unknown if there were any crucial differences with those participants that would have changed the results. The Back-Scratch Test was difficult for people to complete who had shoulder surgery, arthritis, or shoulder pain, and three people did not complete the measure due to pain. The weight specified for the Arm Curl Test was too heavy for participants in this setting to use. In this sample, all participants declined using a weight of any kind, indicating they experienced shoulder pain with a heavier weight. Because this population was not able to complete the arm curl test according to the protocol, normative data or minimal clinically important difference were not able to be interpreted. Finally, because the intervention was offered at ALFs, the yoga sessions were opened to those who were not enrolled; at times non-participant residents caused distractions during the session, which may have participant experience and ultimately impacted outcomes.

\section{Implications for Future Research}

For future research on leisure constraints, we recommended that researchers use or develop a more appropriate scale specific to long-term residential settings. Structural, interpersonal, and intrapersonal constraints should still be evaluated, but the wording could be modified to reflect long-term care facilities rather than community facilities. Future research on leisure constraints in this setting might observe and record the actual activity participation in other exercise and physical activity groups by conducting a chart review instead of relying on self-reports. Improvements in functional fitness were observed, and it is recommended to conduct further evaluation with a larger sample size and an active control group to determine if outcomes of yoga participation differ from outcomes of other physically active interventions. 


\section{Conclusion}

The results of this study indicate that yoga may be a useful intervention for practitioners to implement to promote involvement in additional activities. Results also indicate a yoga intervention may help manage pain, and in improving aspects of physical functioning.

\section{Acknowledgments}

The authors would like to acknowledge Claire K. Allison for her assistance during the intervention and data collection.

\section{Author Contributions}

Em V. Adams designed the study, conducted the data collection, assisted in implementing the intervention, and was the primary author. Marieke Van Puymbroeck assisted in developing the study, provided council during recruitment, and assisted in writing and editing many drafts of the manuscript. Brandi M. Crowe assisted in designing the study, provided guidance through data analysis, and edited several drafts of the manuscript. Cynthia L.S. Pury provided feedback for both the study design and the manuscript. Arlene A. Schmid provided feedback on the study design and edited several drafts of the manuscript.

\section{Competing Interests}

The authors have declared that no competing interests exist.

\section{References}

1. Administration on Aging. Who needs care?- Long-term care information. LTC. 2017. Available from: https://longtermcare.acl.gov/the-basics/who-needs-care.html.

2. WHO. Long-term-care systems. WHO. 2018. Available from: https://www.who.int/ageing/long-term-care/en/.

3. National Center for Health Statistics. Long-term care services in the United States: 2013 Overview. Washington, D.C.: Government Printing Office; 2014.

4. Lampinen $\mathrm{P}$, Heikkinen RL, Kauppinen M, Heikkinen E. Activity as a predictor of mental wellbeing among older adults. Aging Ment Health. 2006; 10: 454-466.

5. Orsega-Smith EM, Payne LL, Mowen AJ, Ho CH, Godbey GC. The role of social support and self-efficacy in shaping the leisure time physical activity of older adutls. J Leis Res. 2007; 39: 705-727.

6. Van Puymbroeck M, Payne LL, Hsieh P-C. A phase I feasibility study of yoga on the physical health and coping of informal caregivers. Evid Based Complement Altern Med. 2007; 4: 519529.

7. Hutchinson SL, Nimrod G. Leisure as a resource for successful aging by older adults with chronic health conditions. Int J Aging Hum Dev. 2012; 74: 41-65.

8. Janke MC, Payne LL, Van Puymbroeck M. The role of informal and formal leisure activities in the disablement process. Int J Aging Hum Dev. 2008; 67: 231-257. 
9. Resnick B, Simpson M, Galik E, Bercovitz A, Gruber-Baldini AL, Zimmerman S, et al. Making a difference: Nursing assistants' perspectives of restorative care nursing. Rehabil Nurs. 2006; 31: 78-86.

10. Tak SH, Kedia S, Tongumpun TM, Hong SH. Activity engagement: Perspectives from nursing home residents with dementia. Educ Gerontol. 2015; 41: 182-192.

11. Crawford DW, Jackson EL, Godbey G. A hierarchical model of leisure constraints. Leis Sci. 1991; 13: 309-320.

12. Benjamin K, Edwards N, Guitard P, Murray MA, Caswell W, Perrier MJ. Factors that influence physical activity in long-term care: Perspectives of residents, staff, and significant others. Can J Aging. 2011; 30: 247-258.

13. Godbey G, Crawford DW, Shen XS. Assessing hierarchical leisure constraints theory after two decades. J Leis Res. 2010; 42: 111-134.

14. Cowan DT, Fitzpatrick JM, Roberts JD, While AE, Baldwin J. The assessment and management of pain among older people in care homes: current status and future directions. Int J Nurs Stud. 2003; 40: 291-298.

15. Pickering G, Deteix A, Eschalier A, Dubray C. Impact of pain on recreational activities of nursing home residents. Aging Clin Exp Res. 2001; 13: 44-48.

16. Takai Y, Yamamoto-Mitani N, Okamoto Y, Koyama K, Honda A. Literature review of pain prevalence among older residents of nursing homes. Pain Manag Nurs. 2010; 11: 209-223.

17. Hubbard J, Mannell RC. Testing competing models of the leisure constraint negotiation process in a corporate employee recreation setting. Leis Sci. 2001; 23: 145-163.

18. Kleiber D, McGuire F, Aybar-Damali B, Norman W. Having more by doing less: The paradox of leisure constraints in later life. J Leis Res. 2008; 40: 343-359.

19. Shores KA, Scott D, Floyd MF. Constraints to outdoor recreation: A multiple hierarchy stratification perspective. Leis Sci. 2007; 29: 227-246.

20. Marsiske $M$, Lang F, Baltes $P$, Baltes $M$. Selective optimization with compensation: Life-span perspectives on successful development. Compensating for Psychological Deficits and Declines: Managing Losses and Promoting Gains. Avenue Mahwah, NJ: Lawrence Erlbaum Associates Inc; 1995. p.35-p.79.

21. Du J. Women's leisure as reproduction and resistance. Affilia. 2008; 23: 179-189.

22. Van Puymbroeck $M$, Smith $R$, Schmid A. Yoga as a means to negotiate physical activity constraints in middle-aged and older adults. Int J Disabil Hum Dev. 2011; 10: 117-121.

23. Van Puymbroeck M, Schmid A, Walter A, Hawkins B. Improving leisure constraints in older adults with a rear of falling through Hatha yoga: An acceptability and feasibility study. Int J Gerontol Geriatr Res. 2017; 1: 7-13.

24. Field T. Yoga clinical research review. Complement Ther Clin Pract. 2011; 17: 1-8.

25. Khalsa SBS, Cohen L, McCall T, Telles S. The Principles and Practice of Yoga in Health Care. Edinburgh: Handspring Publishing; 2016.

26. Wang D. The use of yoga for physical and mental health among older adults: A review of the literature. Int J Yoga Ther. 2009; 19: 91-96.

27. Schmid AA, Miller KK, Van Puymbroeck M, Schalk N. Feasibility and results of a case study of yoga to improve physical functioning in people with chronic traumatic brain injury. Disabil Rehabil. 2016; 38: 914-920. 
28. Wren AA, Wright MA, Carson JW, Keefe FJ. Yoga for persistent pain: New findings and directions for an ancient practice. Pain. 2011; 152: 477-480.

29. Schmid AA, Van Puymbroeck M, Portz JD, Atler KE, Fruhauf CA. Merging Yoga and Occupational Therapy (MY-OT): A feasibility and pilot study. Complement Ther Med. 2016; 28: 44-49.

30. Büssing A, Ostermann $T$, Ludtke R, Michalsen A. Effiects of yoga interventions on pain-and pain-associated disability: A meta-analysis. J Pain. 2012; 13: 1-9.

31. Resnick B, Galik E, Gruber-Baldini AL, Zimmerman S. Perceptions and performance of function and physical activity in assisted living communities. J Am Med Dir Assoc. 2010; 11: 406-414.

32. Schmid AA, Van Puymbroeck $M$, Altenburger PA, Schalk NL, Dierks TA, Miller KK, et al. Poststroke balance improves with yoga: A pilot study. Stroke. 2012; 43: 2402-2407.

33. Schmid AA, Van Puymbroeck $M$, Koceja DM. Effect of a 12-week yoga intervention on fear of falling and balance in older adults: A pilot study. Arch Phys Med Rehabil. 2010; 91: 576-583.

34. Phillips $\amalg$, Flesner M. Perspectives and experiences related to physical activity of elders in long-term-care settings. J Aging Phys Act. 2013; 21: 33-50.

35. Król-Zielińska M, Kusy K, Zieliński J, Osiński W. Physical activity and functional fitness in institutionalized vs. independently living elderly: A comparison of 70-80-year-old city-dwellers. Arch Gerontol Geriatr. 2011; 53: e10-e16.

36. Logan SL, Gottlieb BH, Maitland SB, Meegan D, Spriet LL. The Physical Activity Scale for the Elderly (PASE) questionnaire; does it predict physical health? Int J Environ Res Public Health. 2013; 10: 3967-3986.

37. Adams EV, Crowe BM, Van Puymbroeck M, Alllison CK, Schmid AA. Yoga as a communitybased recreational therapy intervention for older adults: A Pilot Study. Ther Recreat J. 2019; 53: 4.

38. Hawkins BL, Van Puymbroeck M, Walter A, Sharp J, Woshkolup K, Urrea-Mendoza E, et al. Perceived activities and participation outcomes of a yoga intervention for individuals with parkinson's disease: A mixed methods study. Int J Yoga Therap. 2018; 28: 51-61.

39. Van Puymbroeck M, Schmid A, Shinew K, Hsieh PC. Influence of hatha yoga on physical activity constraints, physical fitness, and body image of breast cancer survivors: a pilot study. Int J Yoga Therap. 2011; 21: 49-60.

40. Adams EV, Van Puymbroeck M, Pury CL, Schmid AA. Feasility of implementing therapeutic yoga in assisted living facilities. Ann Behav Med. 2020; 54: S692.

41. Thomas S, Reading J, Shephard RJ. Revision of the physical activity readiness questionnaire (PAR-Q). Can J Sport Sci. 1992; 17: 338-345.

42. Borson S, Scanlan JM, Chen P, Ganguli M. The Mini-Cog as a screen for dementia: Validation in a population-basedsample. J Am Geriatr Soc. 2003; 51: 1451-1454.

43. Johnson DP, Penn DL, Fredrickson BL, Meyer PS, Kring AM, Brantley M. Loving-kindness meditation to enhance recovery from negative symptoms of schizophrenia. J Clin Psychol. 2009; 65: 499-509.

44. Van Puymbroeck M, Walter A, Hawkins BL, Sharp JL, Woschkolup K, Urrea-Mendoza E, et al. Functional improvements in Parkinson's disease following a randomized trial of yoga. Evid Based Complement Altern Med. 2018; 2018: 8516351.

45. Alexandris K, Carroll B. An analysis of leisure constraints based on different recreational sport participation levels: Results from a study in Greece. Leis Sci. 1997; 19: 1-15. 
46. Krebs EE, Lorenz KA, Bair MJ, Damush TM, Wu J, Sutherland JM, et al. Development and initial validation of the PEG, a three-item scale assessing pain intensity and interference. J Gen Intern Med. 2009; 24: 733-738.

47. Rikli R, Jones J. Senior Fitness Test Manual. Champaign, IL: Human Kinetics Publishers, Inc; 2013.

48. Gorman SL, Harro CC, Platko C, Greenwald C. Examining the function in sitting test for validity, responsiveness, and minimal clinically important difference in inpatient rehabilitation. Arch Phys Med Rehabil. 2014; 95: 2304-2311.

49. Miotto JM, Chodzko-Zajko WJ, Reich JL, Supler MM. Reliability and validity of the fullerton functional fitness test: An independent replication study. J Aging Phys Act. 1999; 7: 339-353.

50. Dunsky A, Ayalon M, Netz Y. Arm-curl field test for older women: is it a measure of arm strength? J Strength Cond Res. 2011; 25: 193-197.

51. Boneth Collantes M, Ariza García CL, Angarita Fonseca A, Parra Patiño J, Monsalve A, Gómez E. Reliability of arm curl and chair stand tests for assessing muscular endurance in older people. Rev Ciencias la Salud. 2012; 10: 179-193.

52. Gorman SL, Radtka S, Melnick ME, Abrams GM, Byl NN. Development and validation of the function in sitting test in adults with acute stroke. J Neurol Phys Ther. 2010; 34: 150-160.

53. Hsieh HF, Shannon SE. Three approaches to qualitative content analysis. Qual Health Res. 2005; 15: 1277-1288.

54. Cooper R, Kuh D, Cooper C, Gale CR, Lawlor DA, Matthews F, et al. Objective measures of physical capability and subsequent health: A systematic review. Age Ageing. 2011; 40: 14-23.

55. Adams EV, Taniguchi ST, Ward PJ, Hite SJ, Mugimu CB, Nsubuga YK. Leisure defined by percieving choice: Perspective of Ugandan women. World Leis J. 2018; 60: 265-280.

56. Churchill SL, Clark VL, Prochaska-Cue K, Creswell JW, Ontai-Grzebik L. How rural low-income families have fun: A grounded theory study. J Leis Res. 2007; 39: 271-294.

57. Kahn NA. Leisure and recreation among women of selected hill-farming families in Bangledesh. J Leis Res. 1997; 1: 50-20.

58. Van Puymbroeck M, Burk BN, Shinew KJ, Cronan KM, Schmid AA. Perceived health benefits from yoga among breast cancer survivors. Am J Heal Promot. 2013; 27: 308-315.

59. Damush TM, Kroenke K, Bair MJ, Wu J, Tu W, Krebs EE, et al. Pain self-management training increases self-efficacy, self-management beavhiours and pain and depression outcomes. Eur J Pain. 2016; 20: 1070-1078.

60. Van Puymbroeck M, Atler K, Portz JD, Schmid AA. Multidimensional improvements in health following Hatha Yoga for individuals with diabetic peripheral neuropathy. Int J Yoga Therap. 2018; 28: 71-78.

61. Schmid AA, Miller KK, Van Puymbroeck M, Debaun-Sprague E. Yoga leads to multiple physical improvements after stroke, a pilot study. Complement Ther Med. 2014; 22: 994-1000.

62. Candela F, Zucchetti G, Magistro D. Individual correlates of autonomy in activities of daily living of institutionalized elderly individuals. Holist Nurs Pract. 2013; 27: 284-291. 
OBM Geriatrics 2020; 4(4), doi:10.21926/obm.geriatr.2004135

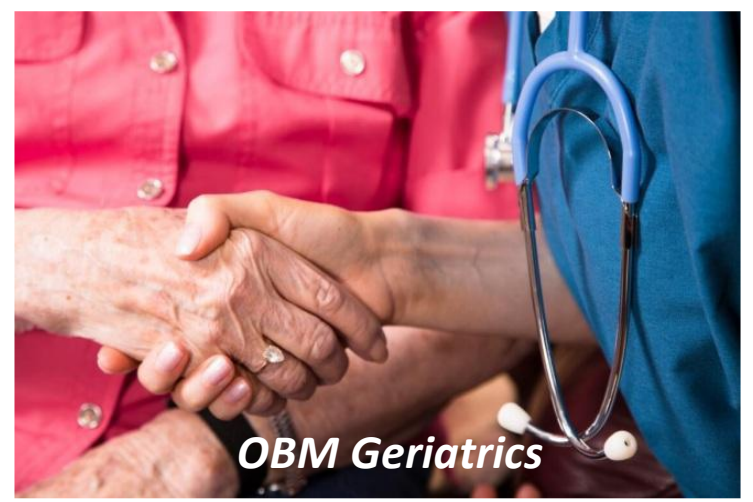

Enjoy OBM Geriatrics by:

1. Submitting a manuscript

2. Joining in volunteer reviewer bank

3. Joining Editorial Board

4. Guest editing a special issue

For more details, please visit:

http://www.lidsen.com/journals/geriatrics 